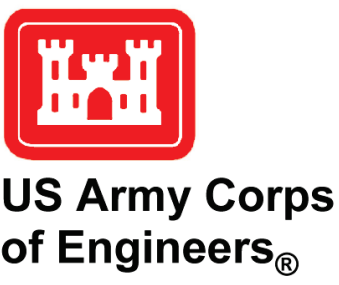

\title{
U.S. Tidal Inlets Atlas: An Update to the CIRP Inlets Database
}

\author{
by Tanya M. Beck and David Arnold
}

PURPOSE: This Coastal and Hydraulics Engineering Technical Note (CHETN) provides an update of the U.S. Federal Tidal Inlets Database originally developed by the U.S. Army Corps of Engineers (USACE), Coastal Inlets Research Program (CIRP), under the U.S. Army Engineer Research and Development Center (ERDC), Navigation Research, Development, and Technology Program. A digital atlas has been deployed for data exploration and feature extraction using the Environmental Systems Research Institute (ESRI) ArcGIS Online (AGOL) portal for the USACE as a web-based map.

INTRODUCTION: Tidal inlets are connecting waterbody features maintained by tidal processes. They serve as conduits for marine transportation between oceans and estuaries and have significant economic, ecologic, and geomorphic value. Management of these features can be a challenge as tidal inlets tend to be dynamic in nature, and therefore information that assists managers in maintaining stable and predictable inlets is valuable. Stakeholders with interests in inlet management are many, but decision makers tend to be local port authorities and federal, state, and local authorities. The USACE represents federal interests as it maintains nearly 153 tidal inlets (Carr and Kraus 2002) as entrance channels to a broad national network of navigable channels that serve commerce and other economic interests. Many states with a significant number of tidal inlets and barrier island chains also manage a significant portion of their tidal inlets, such as those managed by the Florida Department of Environmental Protection (FDEP 2017) through Inlet Management Plans. At the local government and port-authority levels, specific interests for channel position stability, depth, utilization, and transportation safety tend to drive management requirements.

The U.S. Federal Tidal Inlet Database (Carr and Kraus 2002) was developed in 2002 by the CIRP (CIRP 2017), ERDC. It was designed to function as a "continually evolving information center to maintain accuracy in recognition that inlet characteristics change through time" (Carr and Kraus 2002). It originally contained approximately 42 hydraulic, geomorphic, and geometric parameters collected by various sources (Barnard 1998; Jarrett 1976; Marino and Mehta 1986; Walton and Adams 1976; Vincent et al. 1991; Dombrowski 1994), and the dataset was originally focused only on 91 federally maintained inlets. Coupled with aerial photos, the Inlets Database was first posted to a website to facilitate open access (CIRP 2005). Since its inception, other non-federally maintained inlets have been added as well as additional relevant data features. In 2012, additional inlet ebb-tidal delta geomorphic features were measured and appended to the Inlets Database (Carr-Betts et al. 2012). The most recent update included a static web map that lists 200 tidal inlets and a limited number of hydraulic, geomorphic, and engineering features (CIRP 2013).

This effort sought to enhance the existing dataset of information regarding tidal inlets across the United States including seeking out missing data, cross-checking cited data, and compiling references as they relate to inlet management. As the dataset is geospatial in nature, the inlet dataset was converted into a geodatabase with appropriate metadata and then published to the ESRI (AGOL) environment as a web-based mapping application. The web-based map serves as a functional inlet 
search tool that allows decision managers to compare and contrast tidal inlet features and data and review relevant references for decision support. Continued development of this database and webapplication are integral components to the mission of the CIRP, and therefore this phase in development considers improvements in quality control, integration of global user input, increased accessibility, and future potential uses in management needs.

METHODS: In this study, an extensive dataset focused on the geomorphic, hydraulic, and engineering characteristics of tidal inlets across the United States was further developed into a comprehensive geodatabase in the ESRI ArcGIS for use in developing a web-based mapping application. The methods applied in this study fell into four phases: (1) data compilation and quality control, (2) geodatabase development, (3) ebb-tidal delta volume development and computation, and (4) web-based map application development.

Data Compilation and Quality Control. The most recent development of the tidal inlet spreadsheet (Figure 1) had multiple attributes that were grouped broadly in one datasheet. All attributes in this dataset are in SI units and many contain a separate column indicating references for the data. To broaden the applicability of the future database and web application, an additional 135 tidal inlets were added to the database now including 180 federally maintained inlets.

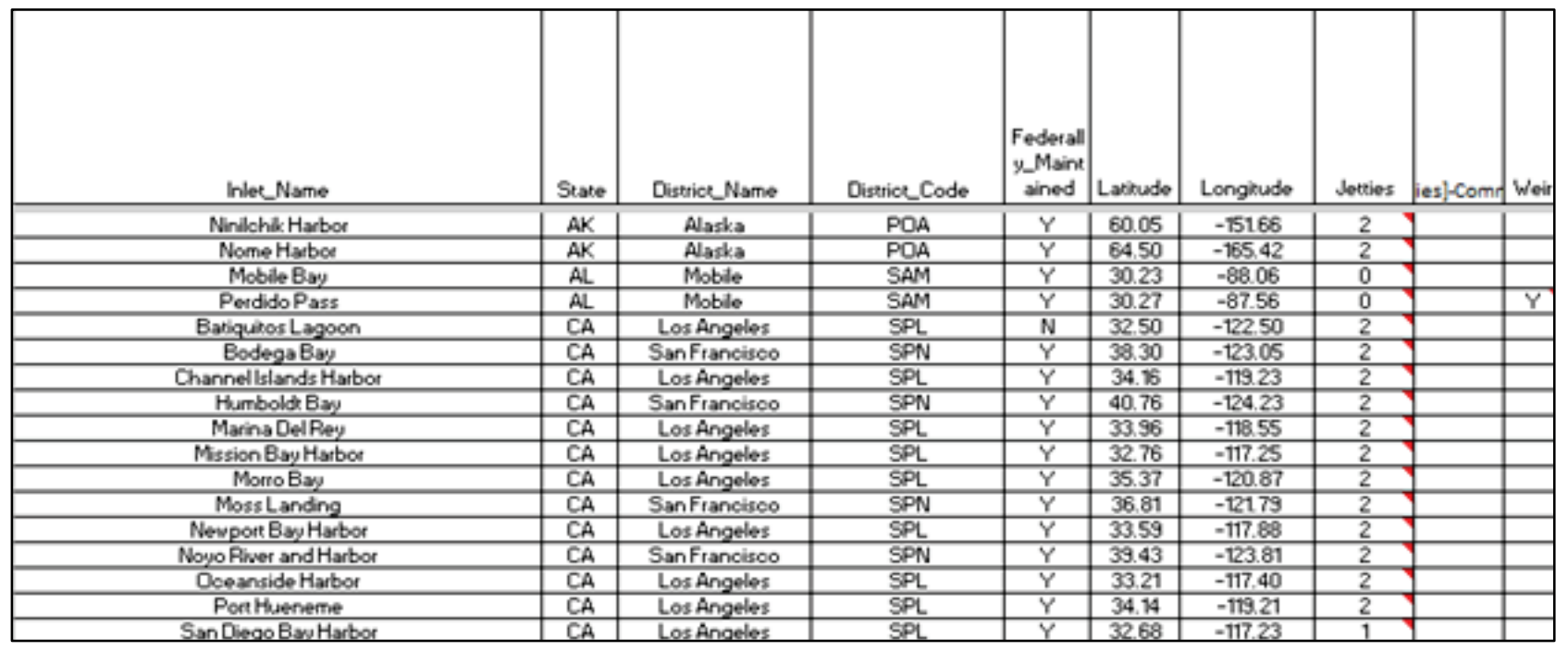

Figure 1. The tidal inlet dataset in spreadsheet form (CIRP 2013). Note that the common identification (ID) feature is based on individual tidal inlets.

Engineering analyses of tidal inlets concerning hydraulic parameters are well documented in this dataset; however, the addition of new referenced parameters is required to make this useful to the engineering community. Tidal inlet shoal volumes are useful in inlet stability and mining/dredging studies, and therefore new columns were added to provide ebb and flood tidal delta shoal volume as well as references. Initial inlet shoal volume data were added from inlet shoal bathymetric data collected prior to 1975 (Walton and Adams 1976). More data will be required for this dataset to become useful in empirical equation development utilizing broad inlet characteristics, a research priority for the CIRP. Additionally, up to six references were collected for inlets along all three coasts (Pacific, Atlantic, and Gulf Coasts) and appended to the end of the dataset. These references consisted 
of technical scientific journal publications, local and state agency reports, and websites with relevant management information.

The attributes (columns in the spreadsheet) were separated into nine separate layers that represent related functional attributes of a tidal inlet. The separate layers contained the randomly generated unique ID, inlet name, and the latitude and longitude. Additional features per layer include the following:

1. Location - USACE District by area of responsibility, and USACE District code.

2. Engineering - Indication of federal maintenance, number of jetties at the entrance channel, length offset between two jetty tips, indication of weir, location of weir (north [N], south [S], east $[\mathrm{E}]$, west $[\mathrm{W}]$ ), and the number of breakwaters along adjacent beaches.

3. Tidal Prism - Tidal prism, local National Ocean Service (NOS) station used in determining tidal range, mean tidal range, and spring tidal range.

4. Dimensions - Minimum inlet width, cross-sectional area, cross-section minimum width as used in cross-sectional area computation, distance to the offshore distal extent of the ebb tidal delta, distance to the downdrift extent of the ebb tidal delta (or position of the downdrift attachment), and distance to the updrift extent of the ebb tidal delta (or position of the updrift attachment).

5. Dredging - Average, minimum, and maximum annual dredging from USACE records for the navigation channel, depth and width of channel dredging at the entrance bar (of the ebb tidal delta), advance (extended) dredged depth and width of channel at the entrance bar, depth and width of dredging of main channel, advance (extended) dredged depth of main channel, and representative average annual entrance dredging (Carr and Kraus 2002).

6. Shoal Volume - Ebb tidal delta (shoal) volume and flood tidal delta (shoal) volume (all in cubic meters).

7. Sediment Transport - Net annual Q sediment transport cited for location, net sediment transport direction in degrees, and net sediment transport direction in N, S, E, W.

8. Sediment Grain Size Distribution - Median sediment grain size in millimeters. Sediment grain size was representative of the adjacent beaches.

9. References - Multiple references associated with management of the inlet.

Geodatabase Development. The nine layers were then appended to a geodatabase and related through a join on a common numeric ID. Metadata for each file within the geodatabase were created, as well as a metadata file for the entire Tidal Inlet Atlas Geodatabase (Figure 2). The Digital Elevation Model (DEM), "Digital Elevation Model NAVD88 Mosaic," created by the National Oceanic and Atmospheric Association (NOAA), National Centers for Environmental Information (NCEI), was resampled to lower resolutions (approximately 6.5 - 25 meters [m]) for separate regions (due to server limitation). The regions were then combined using the Mosaic Catalog and Mosaic Catalog to Raster 
Dataset functions and then clipped using a radial buffer of 7.1 kilometers $(\mathrm{km})$ around each of the inlets. This clipped DEM for each inlet provides elevation raster visualization in addition to base maps and aerial imagery in the geographic information system environment and in the web map. The original DEM by NOAA NCEI did not cover all inlets; approximately 118 inlets had coverage with greater coverage of inlets in Florida, Mississippi, New Jersey, New York, North Carolina, and Oregon.

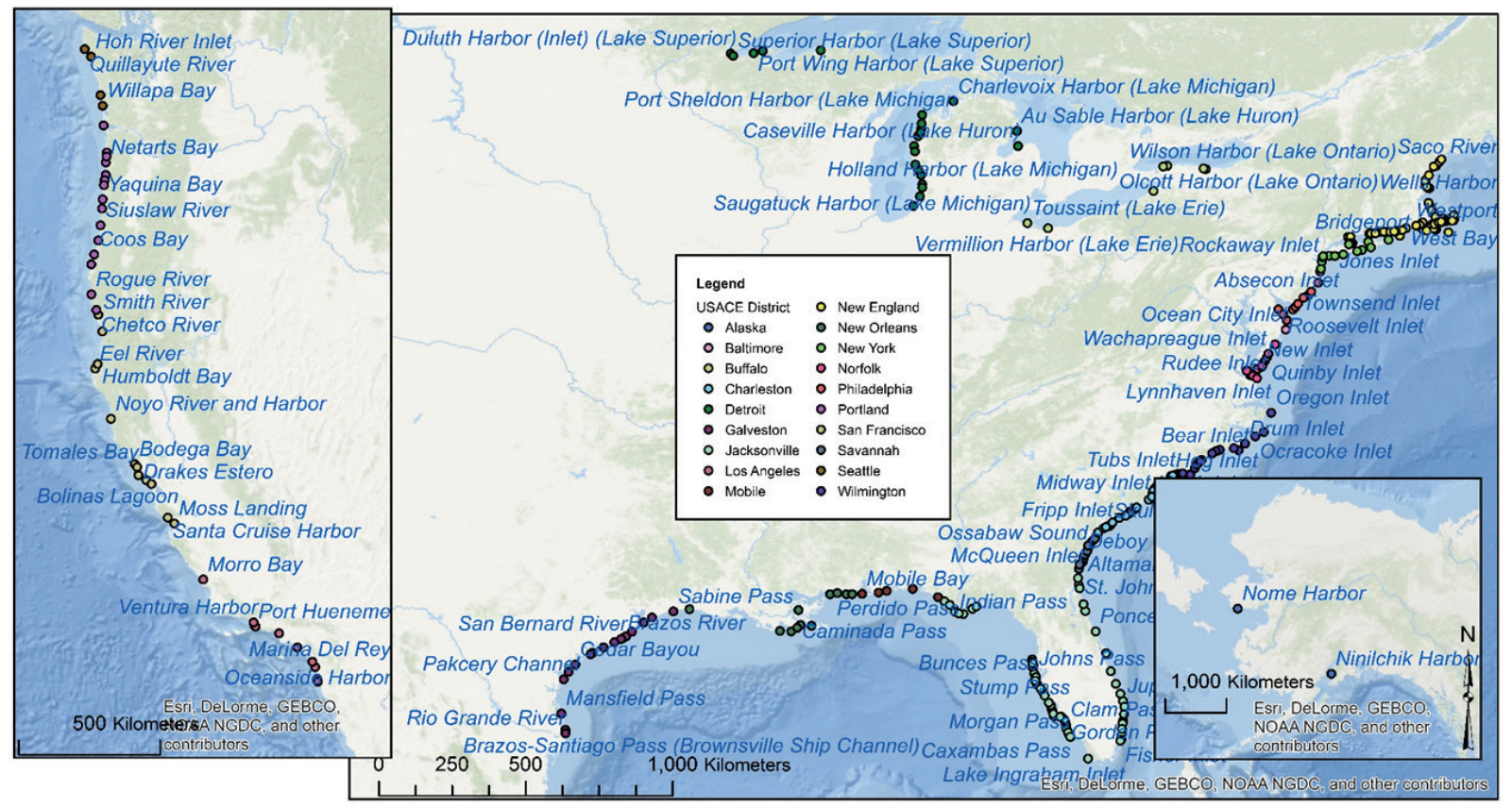

Figure 2. Study area map of the United States illustrating the tidal inlets with colors indicating different USACE Districts. The Tidal Inlet Atlas Geodatabase that includes the nine layers and regional DEMs is centrally inset.

Ebb-Tidal Delta Volume Development and Computation. A new ebb-tidal delta feature class and volume calculation was developed and added to the Tidal Inlet Geodatabase based on The USACE National Coastal Mapping Program's (NCMP) topo-bathymetric lidar datasets collected over multi-year timescales (http://shoals.sam.usace.army.mil/Mapping.aspx). For the initial dataset, a total of 23 inlets were selected along the West-Central Florida coast, where there is high accuracy and coverage in the NCMP datasets. The inlets from north to south included Hurricane Pass (Pinellas County), Clearwater Pass, Johns Pass, Blind Pass (Pinellas County), Pass-A-Grille, Bunces Pass, Longboat Pass, New Pass (Sarasota County), Big Sarasota Pass, Venice Pass, Stump Pass, Gasparilla Pass, Boca Grande Pass (missing two-thirds of ebb-tidal delta), Captiva Pass, Redfish Pass, Blind Pass (Lee County), Big Carlos Pass, Big Hickory Pass, New Pass (Lee County), Delnor-Wiggins Pass, Doctors Pass, Gordon Pass, and Big and Little Marco Passes (combined). Figure 5 illustrates a map of the tidal inlets including area of interest (AOI) reaches for those that calculated ebb-tidal delta volumes. Also included in Figure 3 is an example of the two bounding perpendicular transects along the lateral boundaries of each AOI used in the Trend analysis. 


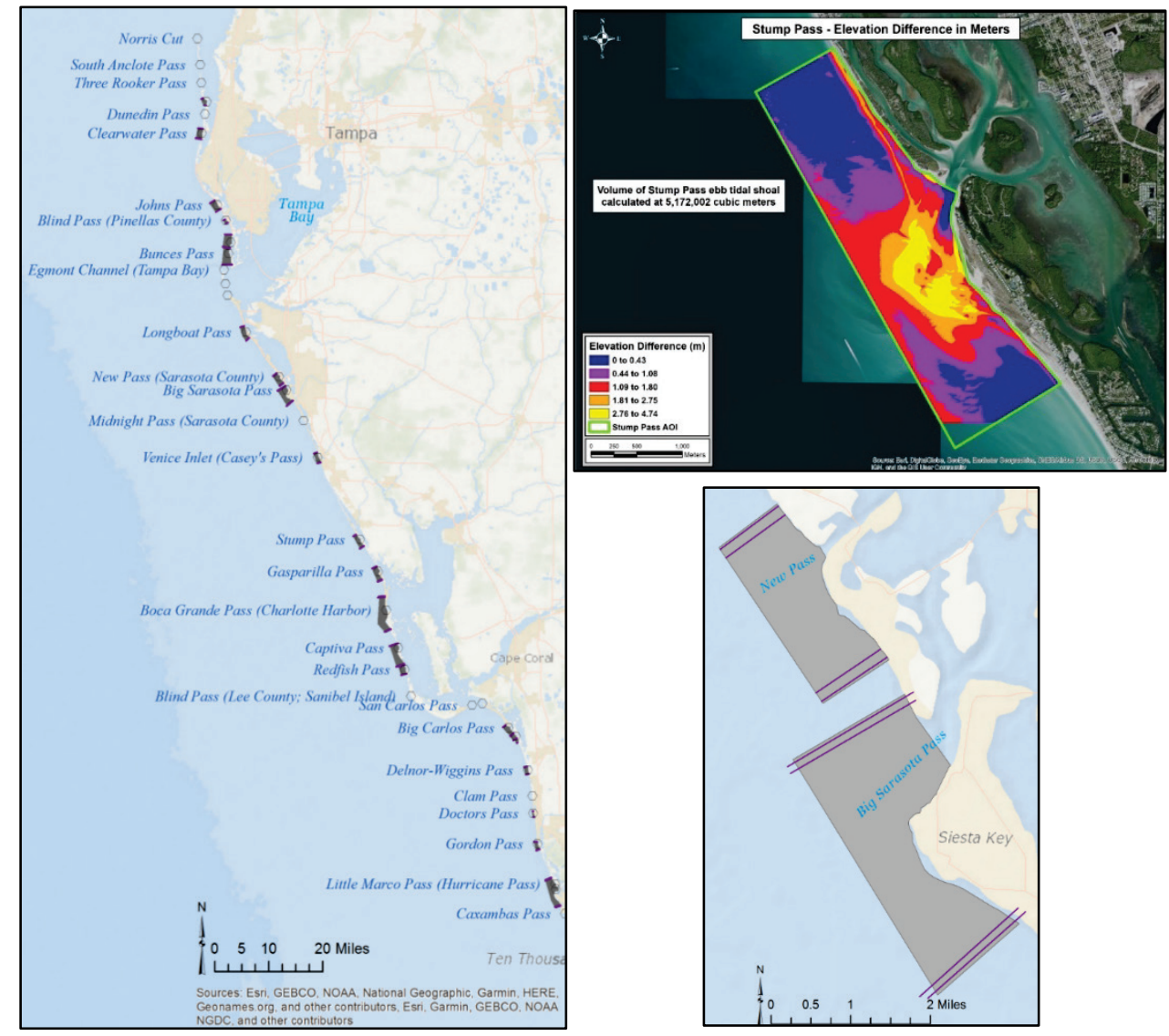

Figure 3. Left: Map of West-central Florida tidal inlets including AOI reaches for the tidal inlets that ebb-tidal delta volumes were computed for. Top right: Example of one tidal inlet ebb-tidal delta volume computation illustrating the elevation difference in meters and the AOI extent. Bottom right: Illustrates the two bounding perpendicular transects along the lateral boundaries of each $\mathrm{AOI}$ used in the Trend analysis.

Lidar bathymetry data collected in 2015 were downloaded from the NOAA Office for Coastal Management's Data Access Viewer (https://coast.noaa.gov/dataviewer). An initial AOI, larger than the inlet's area of influence (beyond closure depth and inlet shoal features), was used to download these data from the NOAA site. The DEM created in the Universal Transverse Mercator Zone 17 projection at a horizontal spatial resolution of 1 meter $(\mathrm{m})$ was selected for ebb-tidal delta volume computation. The ESRI ArcGIS software and Spatial Analyst extension was used for all viewing and processing of the data.

Following the methods outlined in Fontolan et al. (2007), a polygon feature class was created for a refined AOI of each inlet studied. This polygon included the inlet's ebb-tidal delta region plus a length of coastline less than $1 \mathrm{~km}$ on either side of the ebb-tidal delta. A visual inspection of the bathymetry data and the ESRI World Imagery from the ArcGIS Online site was used to determine the extents for the refined AOI. The landward edge of the polygon was the wet/dry line along the coastline, and the seaward side of the AOI was the edge of the DEM where light extinction occurred during lidar acquisition. 
A polyline feature class was used to create four transects of the bathymetric profile. Two perpendicular transects were placed a nominal distance apart at each end of the AOI, trimmed to the AOI and converted to raster cells and later to points. The 2015 bathymetry elevation values were assigned to the transect point locations on the transects. This bathymetry raster was used as the snap raster to which all future rasters were aligned. As a result of being coincident with a no-data raster cell in the 2015 bathymetry, a few transect points received a null value. These points were deleted prior to applying the Trend tool to create a no-inlet bathymetry. No inlet herein refers to the adjacent local trend in offshore bathymetry without the inclusion of the positive relief of the ebb-tidal delta.

The ArcGIS Trend tool (ESRI 2018) allows the creation of a smooth surface by using global polynomial interpolation based on the input of sample points, in this case the transect points containing the 2015 bathymetry data. The user is allowed to select a polynomial order from 1 to 12 with lower polynomial orders generally being better at predicting linear events and higher polynomial orders being better at showing more complex structures. For this study, first-, second-, and third-order polynomial interpolations were run on the transect points to create three distinct no-inlet bathymetry rasters.

Using the Raster Calculator tool, each of the first-, second-, and third-order polynomial no-inlet bathymetry rasters were subtracted from the 2015 bathymetry raster. This resulted in the creation of three residual rasters showing how much sediment had accreted or eroded in each square-meter cell. The three residual rasters were then converted to NumPy arrays, an alternative to raster files to apply Python scripts. The positive values in each NumPy array were summed, resulting in three different values representing sediment volume in cubic meters for each polynomial fit curve. The final selected values were based on the second-order polynomial trend.

The Web-Based Map Application Development. The Tidal Inlet Atlas geodatabase was then added to the ESRI AGOL as feature layers, each displayed in a web map. Individual feature layers were adjusted within the web map to display the primary characteristic of interest in a unique way to demonstrate the variability across the study area of the United States. As an example, dredging records, which are not complete, were displayed as varying size points based on quantity of average annual dredging amounts. This provided a relative scale of the amount of dredging conducted at each inlet. An ESRI World Base Map was added to the background.

After each layer's visible display was set in the web map, a web mapping application was created using an ESRI template for display and analysis using pre-developed widgets. The widgets selected included layer selection list, a bar chart, an overlay analysis calculator, a portal to search and add data from ESRI AGOL and the internet, and a print/share widget.

RESULTS: The Tidal Inlet Atlas Geodatabase is now available for further development by the USACE GIS Technical Center of Expertise. It was published to that user group and is intended to be made public upon review and vetting through a USACE process for GIS data publishing. A series of maps illustrating the tidal inlet atlas features as examples are given in Figures 3-5. Figure 3 illustrates tidal inlet morphology in West-Central Florida with a quantitative representation of ebb tidal delta volume for select inlets that have data. Figure 4 illustrates which of the New Jersey and New York tidal inlets are federally maintained and whether they are structured with one or two jetties. Note that most of the federally maintained inlets along the open Atlantic Ocean coast are structured with two jetties (in 
red). Figure 5 shows tidal inlet dimension data for tidal inlets along the Pacific Northwest coastline with an increasing trend in tidal prism as the bay sizes increase towards the Washington coast.

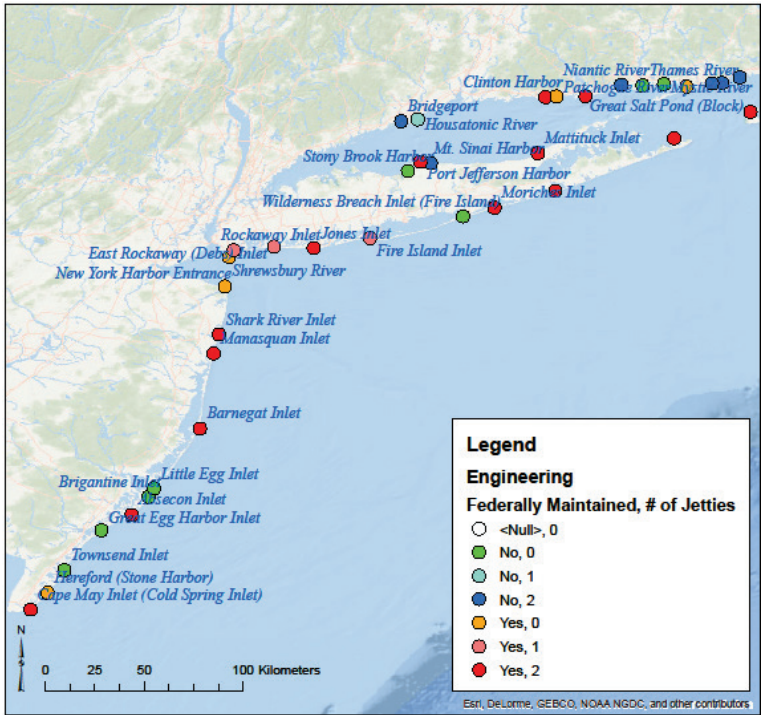

Figure 4. Map of New York-New Jersey Bight illustrating which tidal inlets are federally maintained and whether they are structured with one or two jetties.

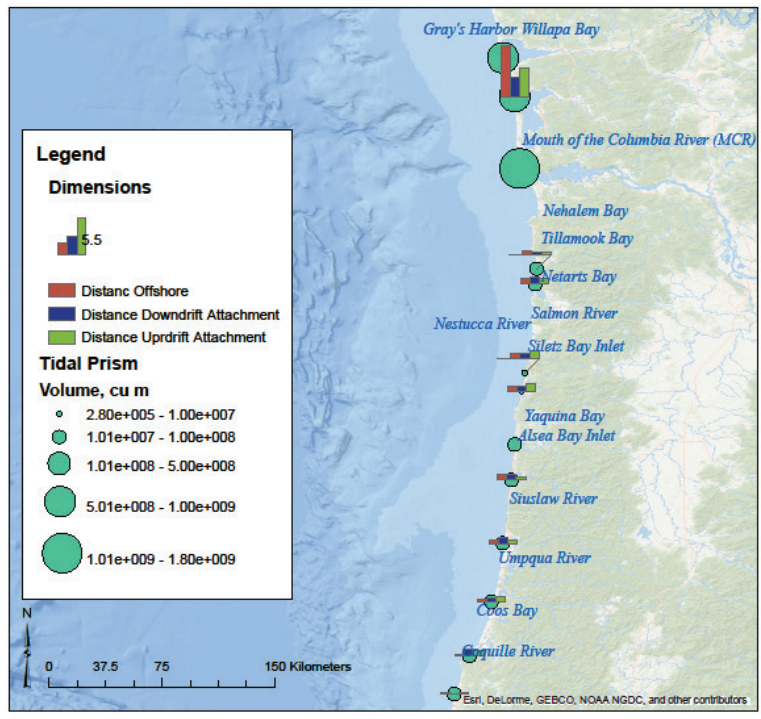

Figure 5. Map of tidal inlet dimension data for tidal inlets along the Pacific Northwest coastline of Oregon and Washington.

The web-based mapping application utilizes the published web map containing the multiple layers of the Tidal Inlet Atlas geodatabase developed for this project. It can be accessed through the CIRP website (http://cirp.usace.army.mil/index.php). It is an interactive website that features GIS widgets that allow the user to do simple analysis and highlight specific features for tidal inlets of interest anywhere in the country. Figure 6 illustrates the details of the application including the functional widgets. Widgets along the left side contain the layer selection list, a bar chart, and an overlay analysis calculator that offers flexibility in analysis of specific features of the inlet and their display within the map window. Additional data can be searched for and added to the map window, and the final map and legend can be printed to a pdf figure or directly to a printer. Users may also select the share tab and get options to share their modified web map directly or embed the resultant map (including all application features) into another website.

DISCUSSION: In this study, four components comprised an effort to expand the tidal inlets database into a more comprehensive dataset with relevant, global availability to users via ArcGIS Online web-based application capabilities. This endeavor is a substantial undertaking that will continue to evolve as more data become available and web-based technology changes. Central to this project was a significant advancement of clarity in a geodatabase environment and public availability. This study successfully produced relevant data products for public consumption. However, there remains a significant amount of work to be conducted with the addition of new data, quality control, full referencing, and validation through the peer-review process. 
Future efforts will further expand the data in this geodatabase and introduce additional time series topobathymetric datasets (e.g., lidar). This will increase the applicability of the geodatabase for geomorphic analyses of environmental and anthropogenic changes to each inlet. New studies can also be added to the reference list, which would result in a living atlas.

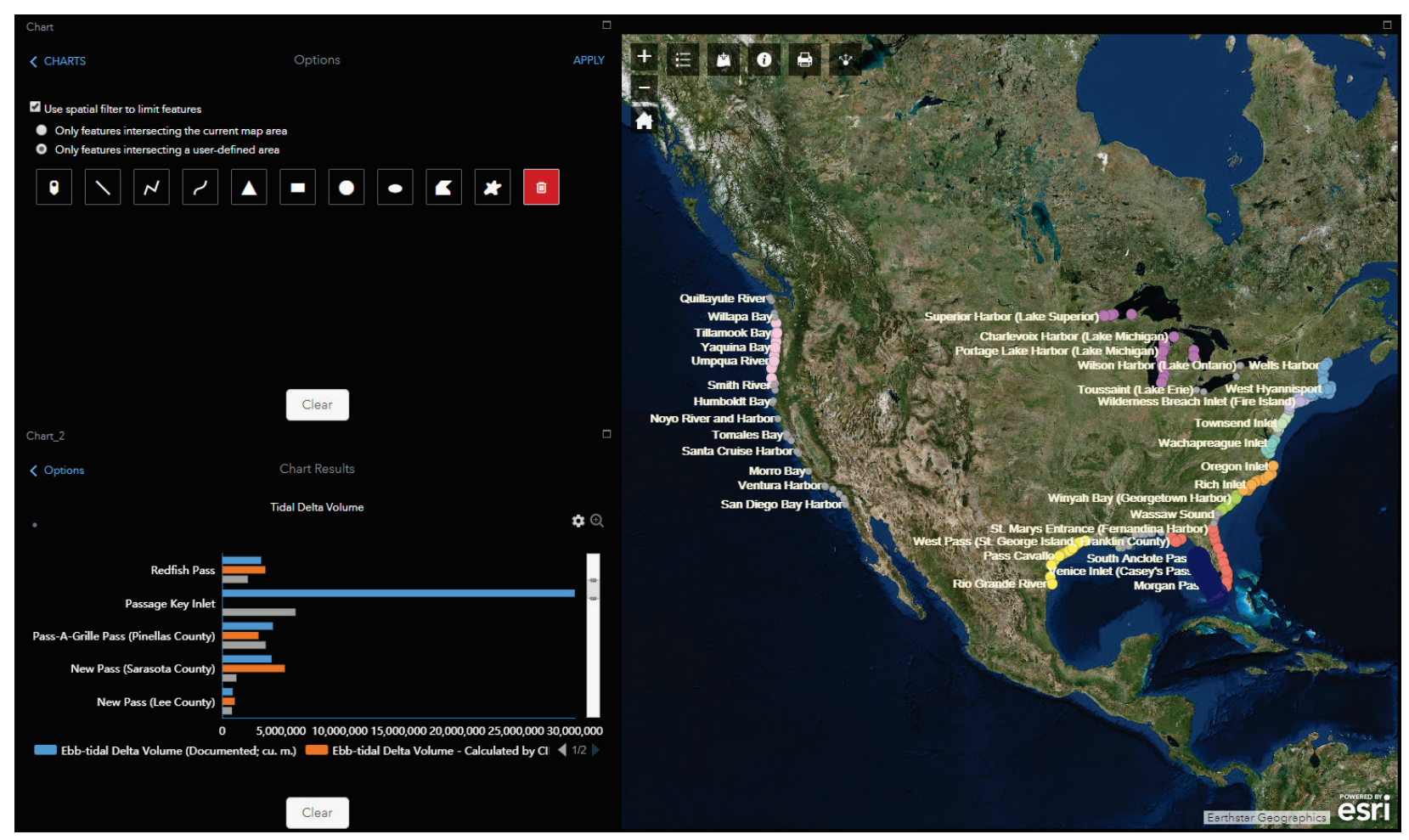

Figure 6. Interactive web-based mapping application for tidal inlets including display, plotting, and analysis widgets. Top-left to bottom-left widgets contain the layer selection list, bar chart, and overlay analysis calculator. The bottom-center widget contains the "data-add" feature, and the bottom-right widget contains the print/share features.

SUMMARY: A tidal inlet data spreadsheet that has been served publicly as flattened web maps in the past has been revived and further developed into a web-based, national geodatabase with new information and clearly articulated references. The geodatabase can be readily accessed and used by other geospatial researchers working with coastal features. An initial feature class has been added to the geodatabase that includes the calculation of 23 tidal inlet ebb-tidal delta volumes with the NCMP bathymetric data product. The datasets have been integrated into an ESRI ArcGIS online web map and interactive web mapping application for decision support analyses. This development effort will facilitate future improvements that include additional quality control efforts, integration of global user input and sourcing for validation, increased accessibility through other digital products, and future potential technological advancements to facilitate management decision support.

ADDITIONAL INFORMATION: This CHETN was prepared by Tanya M. Beck, Tanya.M.Beck@usace.army.mil, and David Arnold, ERDC. Lauren Dunkin and Gregory Dreaper advised on the methods employed in the development of this tool. Erica Carr-Betts contributed 
substantively to the composition of the original dataset. The study was funded by the USACE CIRP. This technical note should be cited as follows:

Beck, T. M., and D. Arnold. 2019. U.S. Tidal Inlets Atlas: An Update to the CIRP

Inlets Database. ERDC/CHL CHETN-IV-118. Vicksburg, MS: U.S. Army

Engineer Research and Development Center.

http://dx.doi.org/10.21079/11681/32666.

\section{REFERENCES}

Barnard, P. L. 1998. Historical Morphodynamics of Inlet Channels West-Central Florida. Thesis, Tampa, FL: University of South Florida.

Carr, E. E., and N. C. Kraus. 2002. Federal inlet database. In Proceedings 2002 National Conference on Beach Preservation Technology Jan 23-25, 2002. Biloxi, MS: FSBPA.

Carr-Betts, E., T. M. Beck, and N. C. Kraus. 2012. Tidal inlet morphology classification and empirical determination of seaward and down-drift extents of tidal inlets. Journal of Coastal Research 28(3): 547-556.

Coastal Inlets Research Program (CIRP). 2005. Inlets Online. Accessed 15 November 2017. http://www.oceanscience.net/inletsonline/

. 2013. Coastal Inlets Research Program: CIRP Viewer Map. Accessed 15 November 2017. http://rscagisu.usace.army.mil/s1portal/apps/OnePane/basicviewer/index.html?appid=5a9f350bdec7485ebceald78bf56 $\underline{437 c}$

2017. Coastal Inlets Research Program. Accessed 15 November 2017. http://cirp.usace.army.mil/

Dombrowski, M. R. 1994. Ebb Tidal Delta Evolution and Navigability in the Vicinity of Coastal Inlets. UFL/COEL99/010. Gainesville, FL: University of Florida Coastal and Oceanographic Engineering Department.

Environmental Systems Research Institute (ESRI). 2018. ArcGIS Pro: Tool Reference - Trend Analysis. Accessed 29 October 2018. http://pro.arcgis.com/en/pro-app/tool-reference/3d-analyst/trend.htm

Florida Department of Environmental Protection (FDEP). 2017. Florida Department of Environmental Protection (FDEP): Strategic Planning and Coordination. Accessed 15 November 2017. https://floridadep.gov/water/beaches-inlets-ports/content/strategic-planning-and-coordination\#IMP

Fontolan, G., S. Pillon, F. Delli Quadri, and A. Bezzi. 2007. Sediment storage at tidal inlets in northern Adriatic lagoons: Ebb-tidal delta morphodynamics, conservation and sand use strategies. Estuarine, Coastal and Shelf Science 75(1-2): 261-277. https://doi.org/10.1016/j.ecss.2007.02.029

Jarrett, J. T. 1976. Tidal Prism-Inlet Area Relationships. GITI-R-3. Vicksburg, MS: Waterways Experiment Station, Coastal Engineering Research Center.

Marino, J. N., and A. J. Mehta. 1986. Sediment Volumes around Florida's East Coast Tidal Inlets. UFL/COEL-86/009. Gainesville, FL: University of Florida Coastal and Oceanographic Engineering.

Vincent, C. L., W. D. Corson, and K. J. Gingerich. 1991. Stability of Selected United States Tidal Inlets. GITI-R-21. Vicksburg, MS: Waterways Experiment Station, Coastal Engineering Research Center. 
May 2019

Walton, T. L., and W. D. Adams. 1976. Capacity of inlet outer bars to store sand. 15th International Conference on Coastal Engineering, July 11-17, 1976, Honolulu, Hawaii, United States, 1919-1937. https://doi.org/10.1061/9780872620834.112

NOTE: The contents of this technical note are not to be used for advertising, publication or promotional purposes. Citation of trade names does not constitute an official 